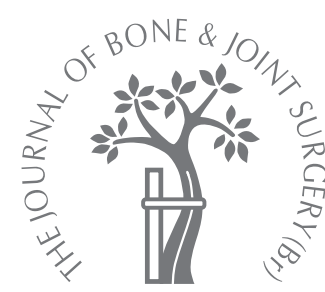

\title{
The responses of extrinsic fibroblasts infiltrating the devitalised patellar tendon to IL-1 $\beta$ are different from those of normal tendon fibroblasts
}

\author{
H. Tohyama, \\ K. Yasuda, \\ H. Uchida, \\ J. Nishihira
}

From Hokkaido

University School of

Medicine, Sapporo,

Japan

\author{
H. Tohyama, MD, PhD, \\ Associate Professor \\ K. Yasuda, MD, PhD, \\ Professor \\ Department of Sports Medicine \\ Hokkaido University School of \\ Medicine, Kita-15 Nishi-7, \\ Sapporo, 060-8638, Japan. \\ - H. Uchida, MD, PhD, \\ Assistant Professor \\ Department of Orthopaedic \\ Surgery, Surgical Science \\ Tokai University School of \\ Medicine, Bohseidai, Isehara, \\ Kanagawa 259-1193, Japan. \\ J. Nishihira, MD, PhD, \\ Professor \\ Department of Medical \\ Information \\ Hokkaido Information \\ University, Nishi-Nopporo,
}

Ebetsu 069-8585, Japan.

Correspondence should be sent to Dr H. Tohyama; e-mail: tohyama@med.hokudai.ac.jp

(C)2007 British Editorial Society of Bone and Joint Surgery doi:10.1302/0301-620X.89B9. $18053 \$ 2.00$

$J$ Bone Joint Surg $[B r]$

2007;89-B:1261-7.
Received 24 April 2006;

Accepted after revision $21 \mathrm{May}$

2007

In order to clarify the role of cytokines in the remodelling of the grafted tendon for ligament reconstruction we compared the responses to interleukin (IL)-1 $\beta$, platelet-derived growth factor (PDGF)-BB and transforming growth factor (TGF)- $\beta 1$ of extrinsic fibroblasts infiltrating the frozen-thawed patellar tendon in rats with that of the normal tendon fibroblasts, in regard to the gene expression of matrix metalloproteinase (MMP)-13, using Northern blot analysis. We also examined, immunohistologically, the local expression of IL$1 \beta$, PDGF-BB, and TGF- $\beta 1$ in fibroblasts infiltrating the frozen-thawed patellar tendon.

Northern blot analysis showed that fibroblasts derived from the patellar tendon six weeks after the freeze-thaw procedure in situ showed less response to IL-1 $\beta$ than normal tendon fibroblasts with respect to MMP-13 mRNA gene expression. The immunohistological findings revealed that IL-1 $\beta$ was over-expressed in extrinsic fibroblasts which infiltrated the patellar tendon two and six weeks after the freeze-thaw procedure in situ, but neither PDGF-BB nor TGF- $\beta 1$ was over-expressed in these extrinsic fibroblasts. Our findings indicated that IL-1 $\beta$ had a close relationship to matrix remodelling of the grafted tendon for ligament reconstruction, in addition to the commencement of inflammation during the tissue-healing process.

It has been shown that in tendon autografts used for the reconstruction of ligaments, repopulation by fibroblasts from an extrinsic origin occurs during revascularisation after the intrinsic fibroblasts in the tendon have died. ${ }^{1-3}$ Numerous studies have shown that various types of cytokine, including interleukin-1 (IL-1), plateletderived growth factor (PDGF) and transforming growth factor-beta (TGF- $\beta$ ), are over-expressed in fibroblasts in the tissue during healing. ${ }^{4}$ These factors are known to regulate the synthesis and degradation of collagen by the fibroblasts. ${ }^{5,6}$ It is therefore possible that extrinsic fibroblasts infiltrating necrotised tendons over-express IL-1, PDGF and TGF- $\beta$. We have previously observed that extrinsic fibroblasts infiltrating necrotic tendons have significantly different biological characteristics from those of intrinsic fibroblasts in normal tendon as regards proliferation and invasive migration into patellar tendon. ${ }^{7}$ There is also a possibility that extrinsic fibroblasts infiltrating the necrotised tendons respond to cytokines differently from the intrinsic fibroblasts in the normal tendon. No studies have compared the responses to cytokines of the two types of fibroblast derived from tendon.

We compared the responses to IL-1 $\beta$, PDGF$\mathrm{BB}$, and TGF- $\beta 1$ of extrinsic fibroblasts infiltrat- ing necrotic patellar tendon and intrinsic fibroblasts in normal tendon as regards the gene expression of matrix metalloproteinase (MMP)13 using Northern blot analysis, and examined immunohistologically the expression of IL-1 $\beta$, PDGF-BB, and TGF- $\beta 1$ in the extrinsic fibroblasts infiltrating the necrotic tendons after freeze-thaw treatment in situ.

\section{Materials and Methods}

We used 15 male 16-week-old Wistar-King rats with a mean weight of $350 \mathrm{~g}$ (330 to $370)$. In order to compare the responses to IL$1 \beta$, PDGF-BB, and TGF- $\beta 1$ of the extrinsic fibroblasts infiltrating the necrotic patellar tendon and the intrinsic fibroblasts, Northern blot analysis was carried out to evaluate the gene expression of MMP-13 in these two types of fibroblast after stimulation with IL$1 \beta$, PDGF-BB or TGF- $\beta 1$. An immunohistological study examined the local expression of IL- $1 \beta$, PDGF-BB, and TGF- $\beta 1$ in the patellar tendon after fibroblast necrosis. All the surgical procedures were carried out in the Institute of Animal Experimentation at Hokkaido University School of Medicine under the Rules and Regulations of the Animal Care and Use Committee. 
Experimental design. For Northern blot analysis, we used nine rats. Freeze-thaw treatment was performed in situ on the right patellar tendons, while the left knees were left untreated. These rats were killed six weeks later and the patellar tendons harvested. The extrinsic fibroblasts and the normal fibroblasts for Northern blot analysis were obtained from both patellar tendons. The remaining six rats were used for immunohistological evaluation. In these we performed freeze-thaw treatment in situ on the right patellar tendon and a sham operation on the left knee. Three were killed at two weeks and the other three at six weeks after surgery, and the patellar tendons on both sides were evaluated immunohistologically.

In situ freeze-thaw procedure. The rats were operated on under sterile conditions and anaesthetised with pentobarbital ( $50 \mathrm{mg} / \mathrm{kg}$, interperitoneally). The patellar tendon was frozen in situ for one minute by liquid nitrogen using a silicone rubber sheet. ${ }^{8}$ The frozen tendon was then thawed using physiological saline. Our previous study had shown that there was no cell outgrowth from explants of the tendons which had undergone this freeze-thaw treatment during incubation for two weeks in the culture medium. ${ }^{8}$

Isolation of fibroblasts. After freeze-thaw treatment of the right patellar tendon, each rat was allowed unrestricted activity in its cage. In a previous study, using an identical procedure, we found that fibroblasts were observed in the anterior and posterior parts of the tendon after three to six weeks, while they were widely distributed throughout the thawed tendon at 12 weeks. ${ }^{8}$ We therefore selected a time point of six weeks because a number of extrinsic fibroblasts would have infiltrated the necrotic patellar tendon by then and there was a possibility that cellular infiltration would be complete by 12 weeks. For each rat, the extrinsic fibroblasts and the normal fibroblasts were obtained from the right patellar tendon six weeks after freeze-thaw treatment and from the left untreated tendon. The outer synovial layer was removed by sharp dissection and the tendons cut into five pieces, $2 \mathrm{~mm}$ to $5 \mathrm{~mm}$ in size, and incubated in Dulbecco's modified Eagle's medium (DMEM) containing $10 \%$ fetal bovine serum (FBS) at $37^{\circ} \mathrm{C}$ in a humidified atmosphere of $5 \% \mathrm{CO}_{2}$ and $95 \%$ air. A confluent monolayer formed for 14 days or less. When the cells became confluent in the primary tissue-culture dishes, we seeded the cultured fibroblasts from the primary tissue culture into a single $60 \mathrm{~mm} \times 15 \mathrm{~mm}$ dish at $10^{5}$ cells at the first passage. They were subcultured at the initial number of $2.5 \times 10^{5}$ cells through the second and third passages. Cells from the third passage were used for all experiments.

Northern blot analysis. To examine the effect of IL-1 $\beta$, PDGF-BB, and TGF- $\beta 1$ on the mRNA expression of MMP13 cultured fibroblasts from the third passage were used throughout the experiment. We used $60 \mathrm{~mm} \times 15 \mathrm{~mm}$ dishes for all Northern blot experiments. After reaching confluence, the fibroblasts were rinsed with phosphatebuffered saline, serum-starved for 24 hours, and challenged with recombinant rat IL-1 $\beta$ (R \& D Systems, Minneapolis,
Minnesota), recombinant human PDGF-BB (R \& D Systems) or recombinant human TGF- $\beta 1$ ( $\mathrm{R} \& \mathrm{D}$ Systems) in $10 \mathrm{ml}$ of serum-free DMEM. Northern blot analyses were performed using the templates of rat MMP-13 and glyceraldehyde-3-phosphate dehydrogenase (GAPDH) cDNA which were obtained from a cDNA library (Takara Bio Inc., Ohtu, Japan) of rat synovial fibroblasts. After hybridisation the RNA was transferred on to a nylon membrane, the radioactive bands were then visualised by autoradiography on Kodak X-AR5 film and quantitatively analysed using the NIH Image system (National Institute of Health, Bethseda, Maryland).

Immunohistological examination. The right patellar tendons of six rats underwent freeze-thaw treatment in situ to devitalise it, ${ }^{8}$ while their left knees had a sham operation. These rats were killed at two and six weeks after the freezethaw treatment and both patellar tendons were evaluated immunohistologically. At two or six weeks the rats were perfused transcardially with $100 \mathrm{ml}$ of $10 \%$ neutral buffered formalin under anaesthesia. Immunohistochemical staining was performed using Histofine Simple Stain Kit (Rat PO Multi; Nichirei, Tokyo, Japan) with anti-IL-1 $\beta$ antiserum (Yanaihara, Shizuoka, Japan), anti-PDGF-BB polyclonal antibody (Santa Cruz Biotechnology, Santa Cruz, California), and anti-TGF- $\beta$ monoclonal antibody (Genzyme, Cambridge, Massachussetts).

Statistical analysis. For each Northern blot procedure, all the intensities of the radioactive bands were standardised with respect to those without cytokine stimulation for normal fibroblasts. The relative intensities of MMP-13 to GAPDH were then compared as an internal control between extrinsic and normal tendon fibroblasts using paired $t$-tests at each condition. We also compared the relative intensities of MMP-13 six hours after cytokine stimulation with those without stimulation using paired $t$-tests for each cytokine. The significance limit was set at $p=0.05$.

\section{Results}

Effects of cytokine stimulation on MMP-13 mRNA expression. We carried out Northern blot analysis for the dose dependency and time course using different cell sources. Stimulation with IL-1 $\beta$ and PDGF increased the MMP-13 gene expression of extrinsic fibroblasts depending on the amount of cytokine up to $10 \mathrm{ng} / \mathrm{ml}$ and $100 \mathrm{ng} / \mathrm{ml} \mathrm{respec-}$ tively, while TGF- $\beta$ stimulation decreased the MMP-13 gene expression for up to $10 \mathrm{ng} / \mathrm{ml}$ (Fig. 1a). The timecourse study showed that the MMP-13 gene expression of fibroblasts increased or decreased with time for up to six hours after cytokine stimulation (Fig. 1b). Therefore, we compared the MMP-13 gene expression of extrinsic fibroblasts with that of normal tendon fibroblasts six hours after stimulation with IL-1 $\beta$ of $10 \mathrm{ng} / \mathrm{ml}$, PDGF of $100 \mathrm{ng} / \mathrm{ml}$ and TGF- $\beta 1$ of $10 \mathrm{ng} / \mathrm{ml}$ (Fig. 1c).

The relative levels of intensity of MMP-13 mRNA were significantly higher in the extrinsic fibroblasts than in the normal patellar tendon fibroblasts (paired $t$-test, $\mathrm{p}=0.010$; 


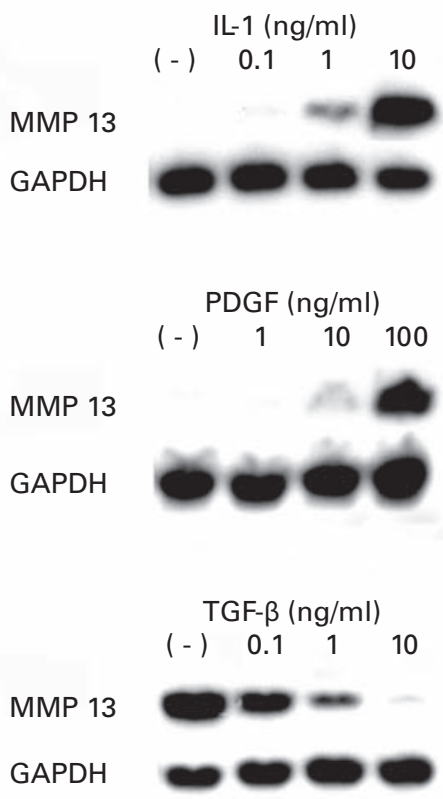

Fig. 1a
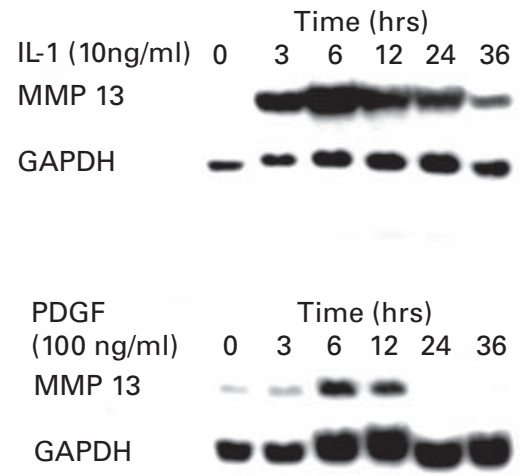

TGF- $\beta$

(10 ng/ml)

Time (hrs)

MMP 13

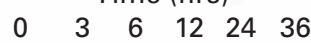

GAPDH

Fig. 1b

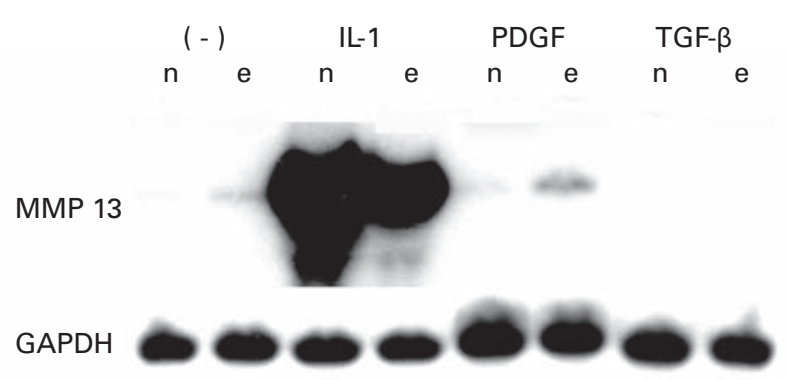

Fig. 1c

Fig. 1 Northern blot analysis of MMP-13 mRNA levels showing a) the effects of the cytokine concentration on MMP-13 mRNA of extrinsic fibroblasts, b) the time course of MMP-13 mRNA of extrinsic fibroblasts after cytokine stimulation and c) the comparison of MMP-13 between normal patellar tendon fibroblasts $(n)$ and extrinsic fibroblasts (e).

Table I). The induction level of MMP-13 mRNA expression by IL-1 $\beta$ stimulation was significantly lower in extrinsic fibroblasts than in the normal patellar tendon fibroblasts (paired $t$-test, $\mathrm{p}=0.005$ ), while IL-1 $\beta$ stimulation significantly increased the MMP-13 mRNA expression in both types (paired $t$-test, $\mathrm{p}=0.001$ ). Stimulation with PDGF-BB did not have a significant effect on the MMP-13 mRNA expression of either type of fibroblast, while the relative level of MMP-13 mRNA after PDGF-BB stimulation was significantly higher in extrinsic fibroblasts than in the normal tendon fibroblasts (paired $t$-test, $\mathrm{p}=0.005$ ). Stimulation with TGF- $\beta 1$ significantly decreased the MMP-13 mRNA expression in both types of fibroblast. There was no significant difference in MMP-13 mRNA expression after
TGF- $\beta 1$ stimulation in extrinsic and normal fibroblasts (paired $t$-test, $\mathrm{p}=0.252$ ).

Local expression of cytokines in extrinsic fibroblasts infiltrating the necrotised tendons. At two weeks after freezethaw treatment, no cells were seen in the deep portion of the midsubstance, while cellular infiltration was observed at the superficial portion close to the infrapatellar fat pad (Fig. 2a) and IL-1 $\beta$-positive cells were found here. At six weeks, a number of fibroblasts were scattered in the tendon and some of these cells expressed IL-1 $\beta$ (Fig. 2b). Tendons with a sham procedure had a minimal amount of staining for IL-1 $\beta$ (Fig $2 \mathrm{c}$ and d). Concerning the local expression of PDGF-BB (Fig. 3) and TGF- $\beta$ (Fig. 4), few positive cells were found in the tendons after the freeze-thaw treatment or the sham operation. 
Table I. Comparison of the MMP-13 gene expression between extrinsic and normal tendon fibroblasts six hours after cytokine stimulation

\begin{tabular}{|c|c|c|c|}
\hline & \multicolumn{2}{|c|}{$\begin{array}{l}\text { Mean ( } \pm \text { SD) relative intensity ratio of MMP-13 } \\
\text { mRNA/GAPDH mRNA }\end{array}$} & \multirow{2}{*}{ p-value } \\
\hline & Extrinsic fibroblasts & Normal fibroblasts & \\
\hline No cytokines & $2.01 \pm 0.48$ & 1.00 & 0.010 \\
\hline $\mathrm{IL}-1 \beta(10 \mathrm{ng} / \mathrm{ml})$ & $13.88 \pm 5.84^{*}$ & $18.48 \pm 7.34^{*}$ & 0.005 \\
\hline PDGF-BB (100 ng/ml) & $2.13 \pm 0.76$ & $1.41 \pm 0.49$ & 0.005 \\
\hline TGF- $\beta(10 \mathrm{ng} / \mathrm{ml})$ & $0.36 \pm 0.19^{*}$ & $0.39 \pm 0.14^{*}$ & 0.252 \\
\hline
\end{tabular}

* significantly different from the values without cytokine stimulation $(p<0.05)$

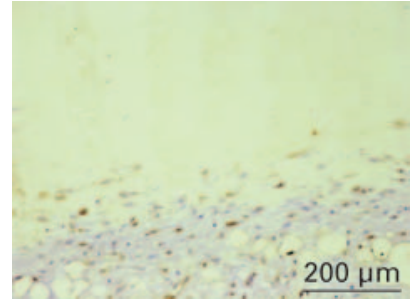

Fig. 2a

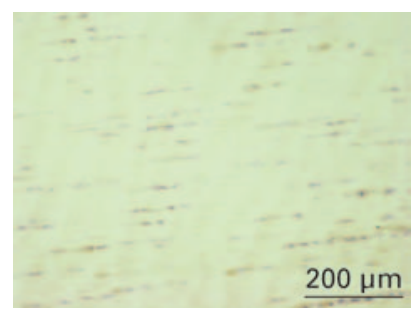

Fig. 2c

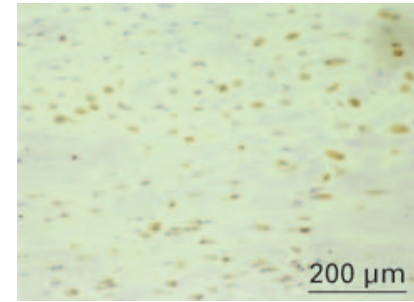

Fig. $2 b$

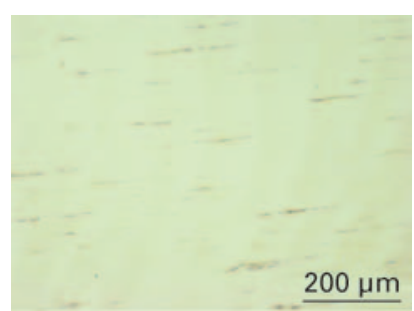

Fig. 2d

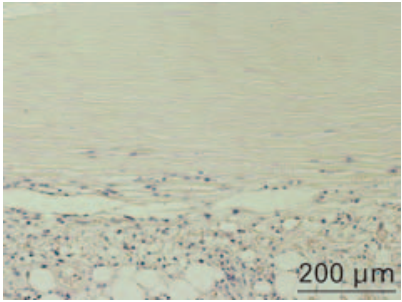

Fig. 3a

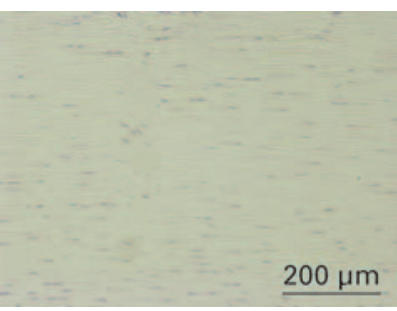

Fig. 3c

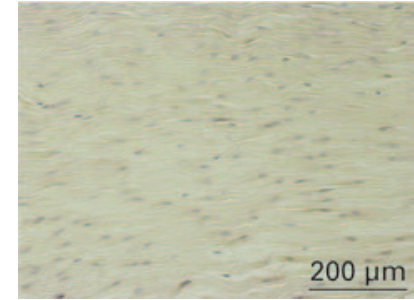

Fig. 3b

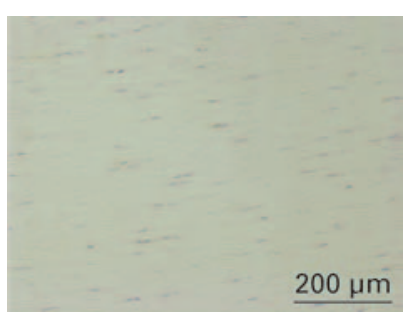

Fig. 3d

Photomicrographs showing the local expression of IL-1 $1 \beta$ in the patellar tendon a) two weeks and b) six weeks after freeze-thaw treatment and c) two and d) six weeks after the sham operation (streptavidin-biotin and haematoxylin $\times 100$ ).

\section{Discussion}

Fibroblasts from an extrinsic origin repopulate the transplanted patellar tendon after fibroblast necrosis during the early phase after ligament reconstruction. These extrinsic fibroblasts remodel the graft matrix. ${ }^{1-3}$ IL-1, PDGF, and TGF- $\beta$ are known to regulate the synthesis and degradation of collagen by the fibroblasts. ${ }^{5,6,9}$ Our study was undertaken to clarify the intrinsic response of the fibroblasts which infiltrate the necrotic patellar tendon to IL-1 $\beta$, PDGF-BB, and TGF- $\beta 1$ by assessing the gene expression of MMP-13. Our findings showed that fibroblasts derived from the patellar tendon six weeks after the freeze-thaw procedure had less response to IL-1 $\beta$ than normal tendon fibroblasts with respect to the regulation of MMP-13 mRNA. IL-1 $\beta$ was found to be over-expressed in the extrinsic fibroblasts which had infiltrated the necrotic patellar tendon.

Photomicrographs showing the local expression of PDGF-BB in the patellar tendon a) two weeks and b) six weeks after freeze-thaw treatment, and c) two and d) six weeks after the sham operation (streptavidinbiotin and haematoxylin $\times 100$ ).
We have previously compared the characteristics of extrinsic fibroblasts with those of normal tendon fibroblasts in a rabbit model. ${ }^{7}$ In the present study we selected the rat model to obtain the antibodies for imunohistology and the probe for Northern blot analysis. Size and species differences may have affected the reliability and validity of this model. Our previous study in rats using the freeze-thaw technique in situ showed that this devitalised all the fibroblasts in the patellar tendon. Extrinsic fibroblasts then entirely infiltrated the patellar tendon by six weeks after freeze-thawing and they expressed more type-III collagen than the fibroblasts in the normal patellar tendon. ${ }^{8}$ In the present study, for the Northern blot analysis we used cells derived from the patellar tendon six weeks after the freezethaw treatment. Immunohistological assessment showed that no cells were seen in the deep portion of the midsub- 


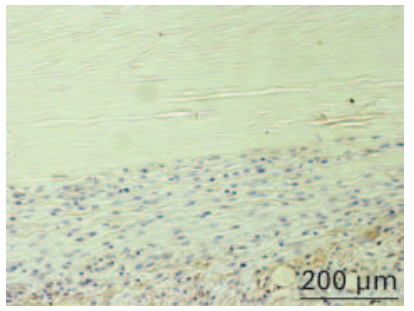

Fig. $4 a$

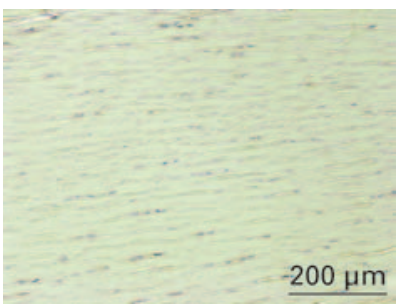

Fig. $4 \mathrm{c}$

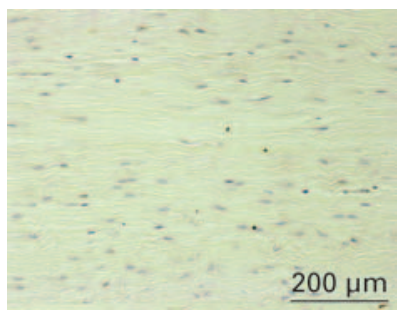

Fig. $4 b$

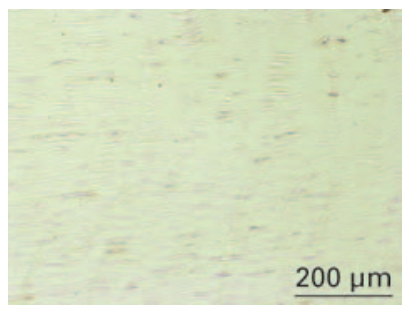

Fig. 4d
Photomicrographs showing the local expression of TGF- $\beta$ in the patellar tendon a) two weeks and b) six weeks after freeze-thaw treatment and c) two and d) six weeks after the sham operation (streptavidin-biotic and haematoxylin $\times 100$ ).

stance two weeks after freeze-thaw treatment, while cellular infiltration was observed at the superficial portion close to the infrapatellar fat pad. Therefore, it was difficult to isolate extrinsic fibroblasts from the patellar tendon two weeks after freeze-thaw treatment, but by six weeks, a number of fibroblasts were scattered in the tendon and we easily obtained extrinsic fibroblasts by using our tissueexplant technique.

With the Northern blot analysis, we evaluated the mRNA of MMP-13 six hours after cytokine stimulation. As shown in Figure 1b, we observed the peak of MMP-13 mRNA in response to IL-1 $\beta$ or PDGF stimulation six hours after stimulation. We therefore used six hours as the time point for evaluation of MMP-13 with Northern blot analysis.

Collagenases are MMPs which can initiate the cleavage of collagen fibrils at neutral $\mathrm{pH} .{ }^{9}$ Three collagenases have been described: collagenase 1 (MMP-1), collagenase 2 (MMP-8), and collagenase 3 (MMP-13). ${ }^{9-11} \mathrm{MMP}-1$ and MMP-13 degrade type-1 collagen fibrils with similar efficiency. ${ }^{9}$ Unlike in man, the rat expresses only one interstitial collagenase, now named MMP-13, because it has a high degree of homology of function and sequence $(86 \%)$ with human MMP-13, but not with human MMP-1. ${ }^{12}$ Consequently, MMP-13 is considered to be central to the process of collagen degradation and matrix breakdown in the rat. The present study demonstrated that IL-1 $\beta$ induced the gene expression of MMP-13 in extrinsic fibroblasts which were derived from the devitalised patellar tendon as well as in normal tendon fibroblasts. It is thought that tendon cells would express receptors and respond to IL-1 in an initial 'molecular inflammation' cascade, the connective tissue-cell expression of cytokines which induce matrix-destructive enzymes. ${ }^{6,13}$ For example, Tuszaki et $\mathrm{al}^{13}$ reported that IL$1 \beta$ stimulated the MMP-1, -3 , and -13 gene expression of normal human tendon cells. Their findings were consistent with those of our present study. Therefore, interstitial collagenases could be induced by IL-1 expressed by the fibroblasts infiltrating the grafted tendon, and such collagenases could then destroy the matrix of the graft during the remodelling of the grafted tendon. A previous study has shown that the expression of mRNA for collagenase in cultured fibroblasts from hypertrophic scars after skin wounds was lower than that from normal dermis. ${ }^{14}$ Another found that no change in MMP-1 or MMP-3 could be shown with stimulation by IL-6 in hypertrophic scar fibroblasts, although mRNA and protein for MMP-1 and MMP-3 were increased by IL-6 in normal skin fibroblasts. ${ }^{15}$ We have previously shown that extrinsic fibroblasts are phenotypically different from normal tendon fibroblasts in terms of proliferation, migration abilities and expression of integrin. ${ }^{7}$ In the present study, we found that extrinsic fibroblasts were less stimulated by IL- $1 \beta$ than normal tendon fibroblasts in terms of the induction of interstitial collagenase mRNA.

Our study has shown over-expression of IL-1 $\beta$ in the tendon graft model, although several other authors have reported that IL-1 $\beta$ was over-expressed in the surrounding tissues of tendons with tendonitis. ${ }^{16-19}$ It is recognised that the level of IL-1 $\beta$ released by neutrophils begins to rise rapidly after wounding and reaches a peak after several hours, suggesting that IL-1 $\beta$ plays an important role in the commencement of inflammation. ${ }^{20,21}$ However, Kondo and Ohshima ${ }^{22}$ observed a second increase in IL-1 $\beta$ at the proliferative stage after wounding in the rat skin, with migration of fibroblasts and the formation of new granulation tissue. We found that the extrinsic fibroblasts which were infiltrating the patellar tendon continued to over-express IL-1 $\beta$ for at least six weeks after necrosis of the intrinsic fibroblasts. These experimental findings indicated that IL-1 $\beta$ had another function with a close relationship to matrix remodelling, in addition to the commencement of inflammation during the process of tissue healing.

IL-1 is a polypeptide which is produced by macrophages, fibroblasts and neutrophils as a response to infection, injury, or antigenic challenges. ${ }^{23}$ After trauma, IL-1 $\beta$ is initially produced by activated macrophages and plays an important role in the initiation of the inflammatory response. It has a close relationship to wound remodelling as well as inflammation. ${ }^{22}$ In general, stimulation of IL-1 increases its synthesis in the autocrine and paracrine fashion and decreases the expression of IL- 1 receptor. ${ }^{24}$ Based on these findings in previous studies and the results of the present investigation, we suggest the following mechanism of the cellular response to graft integration with a cytokine/ cellular control cascade for extrinsic fibroblasts during the 
remodelling of the tendon after fibroblast necrosis. First, IL- $1 \beta$ is produced by macrophages, fibroblasts, and neutrophils surrounding the patellar tendon as a response to the invasive effects of the surgical procedure. Then the secreted IL-1 $\beta$ stimulates the production of collagenase by extrinsic fibroblasts during the infiltration of fibroblasts into the tendon after necrosis of the intrinsic cells. The secreted IL-1 $\beta$ from extrinsic fibroblasts also stimulates the production of IL-1 $\beta$ by the extrinsic fibroblasts themselves in the autocrine and paracrine fashion. IL- $1 \beta$ may reduce IL-1 receptor expression, resulting in the decrease of the responsiveness of extrinsic fibroblasts to IL- $1 \beta$ during the infiltration of extrinsic fibroblasts into the necrotic patellar tendon. Further study should be conducted to verify this hypothesis.

A few limitations are apparent in our study. First, we obtained infiltrative fibroblasts from the patellar tendon after a freeze-thaw treatment which had killed the intrinsic fibroblasts. However, this treatment is not identical to the conditions at tendon grafting and hence the cellular characteristics of infiltrative fibroblasts obtained in the current study may not have corresponded completely to those of fibroblasts in a grafted tendon. Secondly, we evaluated the cellular characteristics at approximately three weeks after harvesting of the patellar tendon. Although we performed only a third passage in the present study because serial passaging diminishes the differences in the phenotypical characteristics of fibroblasts, some cellular characteristics may have changed during the three weeks of culture. Previous studies have shown that the differences in the characteristics of different fibroblasts become insignificant with the serial passaging of the cells. ${ }^{25,26}$ Therefore, the difference in the cellular response to cytokines between extrinsic and normal tendon fibroblasts may have been underestimated in this study. However, many investigators have used the cultured tendon fibroblasts from the third passage or more, ${ }^{9,27,28}$ and we believe that our usage of cultured fibroblasts from the third passage is acceptable. Thirdly, we starved the fibroblasts of serum in the culture medium. This may have affected their differentiation, although the morphological appearances of cells before cytokine stimulation were similar to those before FBS starvation in the present experiments. In the present study we did not apply FBS 24 hours before cytokine stimulation because the existence of cytokines in FBS probably affected the response to additional cytokine stimulation. Based on previous studies, ${ }^{29-31}$ the mean concentration of IL- $1 \beta$, PDGF and TGF- $\beta 1$ in human serum is approximately $2 \mathrm{pg} / \mathrm{ml}, 2 \mathrm{ng} / \mathrm{ml}$ and $40 \mathrm{ng} / \mathrm{ml}$, respectively. Therefore the amounts of PDGF and TGF- $\beta 1$ in FBS are not considered to be negligible compared with the amounts which we applied as cytokine stimulation. The fourth limitation is that we compared the response of extrinsic fibroblasts to cytokine stimulation in terms of MMP-13 under the condition which we had observed to have the most significant effect on cytokine stimulation of gene expression of extrinsic cells in the time-course and the dose-dependency experiments. We had no such information concerning the effect on gene expression in normal tendon fibroblasts. There is therefore, a possibility that we have overestimated the response of the extrinsic fibroblasts to cytokine stimulation in terms of MMP-13 mRNA compared with that of normal fibroblasts. In spite of this, we observed less response of the extrinsic fibroblasts to IL- $1 \beta$ stimulation in terms of MMP-13 mRNA than in normal tendon fibroblasts.

An anti-IL-1 $\beta$ strategy has attracted interest as a clinical treatment for inflammatory diseases such as a rheumatoid arthritis. $^{32}$ The findings of our study indicate that IL-1 $\beta$ is significantly involved in the remodelling of the grafted tendon after reconstruction of the ligament. Inhibition of IL-1 $\beta$ may prevent degradation of the graft and our study highlights a possible application of anti-IL-1 $\beta$ strategy for reducing the mechanical deterioration of grafted tendons after ligament reconstruction.

No benefits in any form have been received or will be received from a commercial party related directly or indirectly to the subject of this article.

\section{References}

1. Arnoczky SP, Tarvin GB, Marshall JL. Anterior cruciate ligament replacement using patellar tendon: an evaluation of graft revascularization in the dog. J Bone Joint Surg [Am] 1982;64-A:217-24.

2. Kleiner JB, Amiel D, Roux RD, Akeson WH. Origin of replacement cells for the anterior cruciate ligament autograft. J Orthop Res 1986;4:466-74.

3. Amiel D, Kleiner JB, Akeson WH. The natural history of the anterior cruciate ligament autograft of patellar tendon origin. Am J Sports Med 1986;14:449-62.

4. Hsu C, Chang J. Clinical implications of growth factors in flexor tendon wound healing. J Hand Surg [Am] 2004;29:551-63.

5. Marui T, Niyibizi C, Georgescu HI, et al. Effect of growth factors on matrix synthesis by ligament fibroblasts. J Orthop Res 1997;15:18-23.

6. Chang YC, Yang SF, Lai CC, Liu JY, Hsieh YS. Regulations of matrix metalloproteinase production by cytokines, pharmacological agents and periodontal pathogens in human peridontal ligament fibroblasts cultures. J Peridontal Res 2002;37:196-203.

7. Ikema $\mathbf{Y}$, Tohyama $\mathbf{H}$, Nakamura $\mathbf{H}$, Kanaya F, Yasuda $\mathbf{K}$. Growth kinetics and integrin expression of fibroblasts infiltrating devitalised patellar tendons are different from those of intrinsic fibroblasts. J Bone Joint Surg [Br] 2005;87-B:1689-93.

8. Tohyama H, Yasuda K, Uchida H. Is the increase in type III collagen of the patellar tendon graft after ligament reconstruction really caused by "ligamentization" of the graft? Knee Surg Sports Traumatol Arthrosc 2006;14:1270-77.

9. Knauper V, Will H, Lopez-Otin C, et al. Cellular mechanisms for human procollagenase-3 (MMP-13) activation: evidence that MT1-MMP (MMP-14) and gelatinase a (MMP-2) are able to generate active enzyme. J Biol Chem 1996;271:17124-31.

10. Freije JM, Diez-Itza I, Balbin M, et al. Molecular cloning and expression of collagenase-3, a novel human matrix metalloproteinase produced by breast carcinomas. $J$ Biol Chem 1994;269:16766-73

11. Mauviel A. Cytokine regulation of metalloproteinase gene expression. J Cell Biochem 1993;53:288-95.

12. Cao Q, Mak KM, Lieber CS. Dilinoleoylphosphatidylcholine prevents transforming growth factor-beta1-mediated collagen accumulation in cultured rat hepatic stellate cells. J Lab Clin Med 2003;139:202-10.

13. Tsuzaki M, Guyton G, Garrett W, et al. IL-1 beta induces COX2, MMP-1, -3 and -13 , ADAMTS-4, IL-1 beta and IL-6 in human tendon cells. J Orthop Res 2003;21:256-64.

14. Arakawa M, Hatamochi A, Mori $\mathbf{Y}$, et al. Reduced collagenase gene expression in fibroblasts from hypertrophic scar tissue. Br J Dermatol 1996;134:863-8.

15. Dasu MR, Hawkins HK, Barrow RE, Xue H, Herndon DN. Gene expression profiles from hypertrophic scar fibroblasts before and after IL-6 stimulation. J Pathol 2004;202:476-85.

16. Blaine TA, Kim YS, Voloshin I, et al. The molecular pathophysiology of subacromial bursitis in rotator cuff disease. J Shoulder Elbow Surg 2005;14(Suppl 1):84-9.

17. Gotoh M, Hamada K, Yamakawa H, et al. Significance of granulation tissue in torn supraspinatus insertions: an immunohistochemical study with antibodies against interleukin-1 beta, cathepsin D, and matric metalloprotease-1. J Orthop Res $1997 ; 15: 33-9$ 
18. Gotoh M, Hamada K, Yamakawa H, et al. Perforation of rotator cuff increases interleukin 1 beta production in the synovium of glenohumeral joint in rotator cuff diseases. J Rheumatol 2000;27:2886-92.

19. Sakai H, Fujita K, Sakai Y, Mizuno K. Immunolocalization of cytokines and growth factors in subacromial bursa of rotator cuff tear patients. Kobe J Med Sci2001:47:2534.

20. Fahey TJ 3rd, Sherry B, Tracey KJ, et al. Cytokine production in a model of wound healing: the appearance of MIP-1, MIP-2, cachectin/TNF and IL-1. Cytokine 1990;2:92-9.

21. Grellner W, Georg T, Wilske J. Quantitative analysis of proinflammatory cytokines (IL-1 beta, IL-6, TNF-alpha) in human skin wounds. Forensic Sci Int 2000;113:251-64.

22. Kondo T, Ohshima T. The dynamics of inflammatory cytokines in the healing process of mouse skin wound: a preliminary study for possible wound age determination. Int J Legal Med 1996;108:231-6.

23. Neta R, Oppenheim JJ. Why should internists be interested in interleukin-1? Ann Intern Med 1988;109:1-3.

24. Dinarello CA. Biologic basis for interleukin-1 in disease. Blood 1996;87:2095-147.

25. Nagineni CN, Amiel D, Green MH, Berchuck M, Akeson WH. Characterization of the intrinsic properties of the anterior cruciate and medial collateral ligament cells: an in vitro cell culture study. J Orthop Res 1992;10:465-75.
26. Hannafin JA, Attia ET, Warren RF, Bhargava MM. Characterization of chemotactic migration and growth kinetics of canine knee ligament fibroblasts. J Orthop Res 1999;17:398-404

27. Archambault J, Tsuzaki M, Herzog W, Banes AJ. Stretch and interleukin-1 beta induce matrix metalloproteinase in rabbit tendon cells in vitro. J Orthop Res 2002;20:36-9.

28. Chan BP, Chan KM, Maffulli N, Webb S, Lee KK. Effect of basic fibroblast growth factor: an in vitro study of tendon healing. Clin Orthop 1997;342:239-47.

29. Sadeghi M, Daniel V, Naujokat C, Weimer R, Opelz G. Strikingly higher interleukin (IL)-1alpha, IL-1beta and soluble interleukin-1 receptor antagonist (sIL-1RA) but similar IL-2, IL-3, IL-4, IL-6, sIL-6R, IL-10, tumour necrosis factor (TNF)-alpha, transforming growth factor (TGF)-beta and interferon IFN-gamma urine levels in healthy females compared to healthy males: protection against urinary tract injury? Clin Exp Immunol 2005;142:312-17.

30. Kropf J, Schurek J0, Wollner A, Gressner AM. Immunological measurement of transforming growth factor-beta 1 (TGF-beta1) in blood: assay development and comparison. Clin Chem 1997;43:1965-74

31. Eppley BL, Woodell JE, Higgins J. Platelet quantification and growth factor analysis from platelet-rich plasma: implications for wound healing. Plast Reconstr Surg 2004;114:1502-8.

32. Afeltra A. Treatment of rheumatoid arthritis: new therapeutic approaches with biological agents. Curr Drug Targets Immune Endocr Metabol Disord 2001;1:45-65. 